\title{
DEVELOPMENT AND APPLICATIONS OF SIMULATION TOOLS FOR ONE-OF-A-KIND PRODUCTION PROCESSES
}

\author{
Dirk Steinhauer \\ Michael Soyka \\ Flensburger Schiffbau-Gesellschaft mbH \& Co. KG \\ Batteriestr. 52 \\ D-24939 Flensburg, GERMANY
}

\begin{abstract}
Since 1997 the simulation team at Flensburger Shipyard has been developing simulation tools for the requirements of one-of-a-kind production processes. Compared to simulation applications in series production there is a strong need for a flexible modeling approach to cover all variants of assembly and logistics operations in site production. To meet these requirements Flensburger Shipyard developed the Simulation Toolkit Shipbuilding (STS) as the modeling backbone of all simulation activities.

At Flensburger Shipyard simulation tools are applied in various ways. Facility layout planning is supported as well as continuous production planning and control. Especially the application in production planning results in a strong benefit in one-of-a-kind production. Planning reliability and productivity can be increased by the dynamic and detailed analysis of the upcoming production program. This paper shows the general modeling approach as well as applications for simulations aided production planning in part production and complex assembly including outfitting.
\end{abstract}

\section{INTRODUCTION}

The production process in shipbuilding is defined by the complex product ship. A ship can be considered as a one-of-a-kind product even in small series due to constant changes of design and building method. Therefore, production development as well as production planning and control feature specific requirements in shipbuilding with respect to the complexity of the processes and the availability of data.

Shipbuilding simulation does not only have specific restrictions, but it also offers specific potentials. In one-of-a-kind production processes, simulation is of value not only for strategic process development like layout planning projects but also for the continuous application integrated in production planning and control. Every day's unique situations can be evaluated dynamically to provide a better forecast on the one hand and a better basis for decisions on the other hand.

Facing these potentials and failing with sufficient tools available Flensburger Shipyard had founded a simulation team in 1997 to develop simulation tools for shipbuilding processes and simulation applications for production planning and control. To meet the requirements of simulating shipbuilding processes the simulation team developed the Simulation Toolkit Shipbuilding (STS) as the modeling backbone of all simulation activities.

At Flensburger Shipyard the simulation tools are applied in various ways. Facility layout planning is supported as well as continuous production planning and control. Especially the application in production planning results in a strong benefit in one-of-a-kind production.

This paper presents Flensburger Shipyard's simulation approach and the fields of application focusing on the integration of simulation in production planning and control. This strategy of Simulation Aided Production Planning (SAPP) is exemplified with the help of an application in part manufacturing. 


\section{SPECIFICS OF SIMULATION OF ONE-OF-A-KIND PRODUCTION PROCESSES}

The shipbuilding process is considered as a one-of-a-kind production process in a way that not the type of process to be executed is unique but the combination of processes and their occurrence. With every new ship different constraints define the building method and result in new arrangements of activities.

The simulation of production and logistics is rarely used in one-of-a-kind production today. The main reasons are the extensive effort currently needed for building the models and the lack of detailed data about the product in the planning phase. In contrast to stationary series production, one-of-a-kind production does not focus on strategic process improvements. Instead, the emphasis is put on support of the production planning and control. An important aspect is the evaluation of feasibility and robustness of production schedules. This evaluation is conducted not only in advance of the production, but also during the project to take changed basic conditions of the production or modifications of the product into account.

Another important aspect of one-of-a-kind production is the large number of inevitable disturbances in production with consequences that allow no simple evaluation because of the complexity of the processes. With the help of simulation it is possible to perform a sensitivity analysis to identify the critical processes that influence the overall performance of the production system. Actions to compensate disturbances without using a simulation approach tend to fail the desired effect or are over-engineered.

In the field of complex one-of-a-kind-projects it is rarely possible to transfer the simulation models from other projects. In contrast to stationary series production processes which allow the reuse of models it is often necessary to create new models for each project. Even if it is possible to transfer basic operating sequences from previous projects, each project has specific constraints that have to be considered in the simulation model. Therefore it is necessary to enable a quick and flexible model building process.

In addition to the definition of the simulation model, the inadequate availability of data about the product and the processes poses another important challenge for the simulation of one-of-a-kindproduction. The data of the product is often not complete, when the production has already started. Another factor is the occurrence of changes in the product or in the corresponding processes during the production phase. The simulation model has to be adaptable to evaluate the influences of these changes according to the production schedule. To avoid the necessity to implement these changes manually, the simulation environment has to be flexible, allowing modification of product and processes through input from the simulation's database.

\section{FLENSBURGER'S SIMULATION APPROACH}

Flensburger's simulation team gained the first experiences in simulation in the middle of the 1990s evaluating different production concepts for part fabrication and pre-production. These first studies demonstrated not only the potentials in using the simulation in shipbuilding but also the challenges in applying the technology. Therefore the work focussed at first on the development of a toolkit covering the requirements of shipbuilding and later on the data acquisition in order to use the simulation continuously in production planning and control.

\subsection{The Simulation Toolkit Shipbuilding (STS)}

Building simulation models of production processes can be done effectively and efficiently using predefined object libraries. When Flensburger started using simulation the simulation tools available were not sufficient for the usage in shipbuilding since the development of these tools was primarily initiated and driven by the automotive industries. The demands of the shipbuilding industries could not be met by the existing libraries. The main reason was their focus on line oriented production processes whereas site production typically is used in shipbuilding. Furthermore the work packages to be managed in shipbuilding are a lot more complex.

At Flensburger shipyard the development of a library of reusable simulation tools for shipbuilding procedures started in the year 2000 (Steinhauer 2011). The Simulation Toolkit Shipbuilding (STS) is based on the simulation software Plant Simulation by Siemens PLM. Plant Simulation as an object orient- 


\section{Steinhauer and Soyka}

ed simulation software provides the functionality for programming and administrating reusable simulation modules.

The STS contains a large variety of simulation tools for material flow modeling, model management, definition of execution strategies, data input, and output analysis. A selection of tools is shown in Figure 1. In the meantime only few tools are still strongly related to shipbuilding production respectively to steel fabrication aspects. Most of the tools provide a more general functionality for fabrication, assembly and logistics usable in many industries having production conditions comparable to shipbuilding.

Today the STS is the backbone of the simulation work at Flensburger Shipyard as well as in other companies, universities and research institutes not only related to shipbuilding but also to other industries like the construction industry. Modeling expertise from different branches and application scenarios meet in the STS and further the development of its tools.

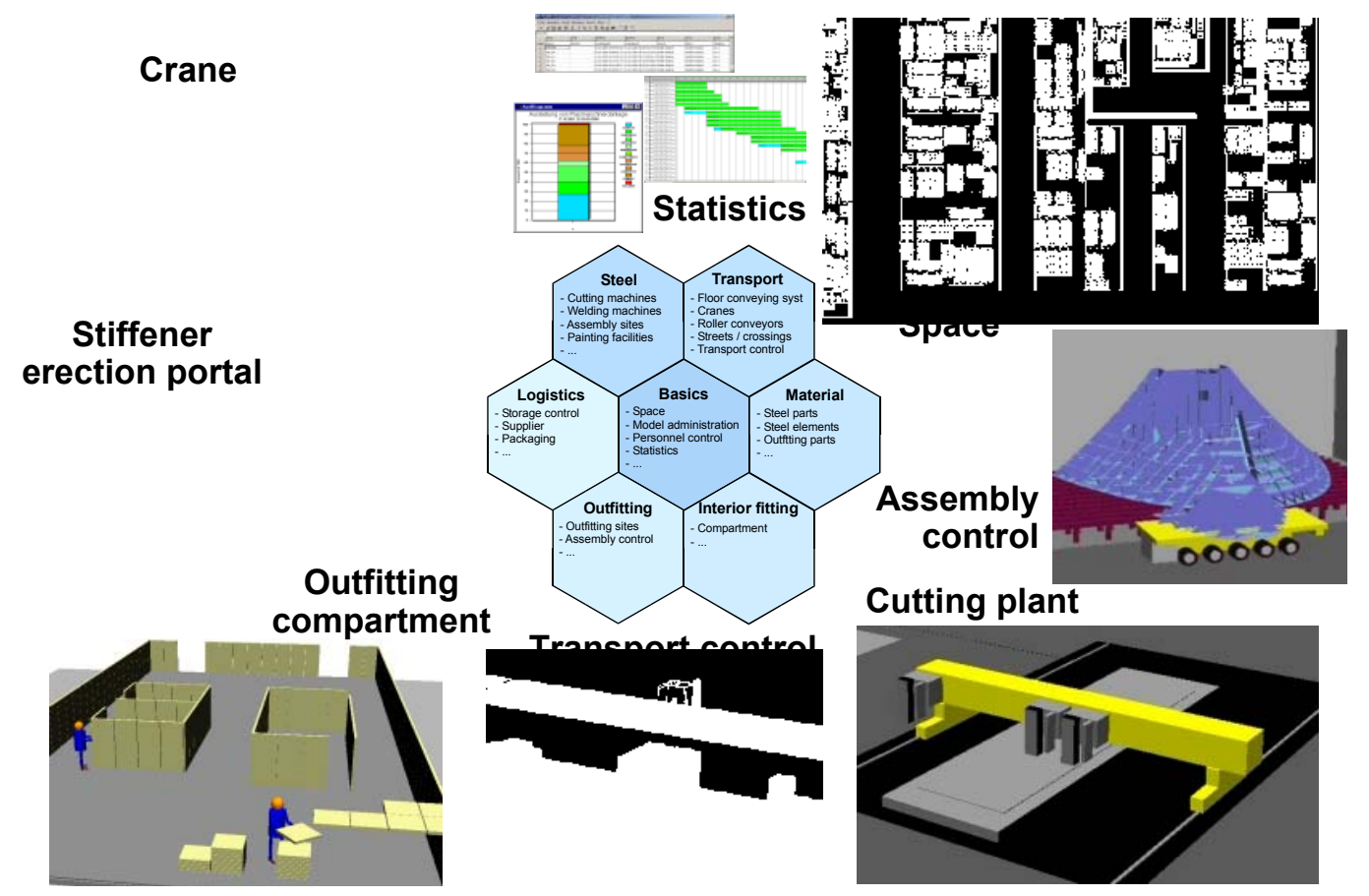

Figure 1: Selection of simulation tools provided by STS

One important aspect of the STS' philosophy is the cooperative development. The simulation team at Flensburger shipyard would not be able to build up, maintain and develop such a software package on its own. Therefore cooperation communities where founded to develop the tools and to organize the application. Requirements for further development from application cases in different industries are coordinated and integrated to bring up general solutions for the simulation challenges.

The first cooperation founded in the field of simulation was the Simulation Cooperation in the Maritime Industries (SimCoMar, www.simcomar.com) bringing together shipyards, universities, and a research institute. SimCoMar has become the maritime forum for the joint development of new or existing simulation tools, for mutual support in implementation of simulation technology and for initiating research and development in the field of simulation.

In 2006, SIMoFIT (Simulation of Outfitting in Shipbuilding and Civil Engineering, www.simofit.com) was founded as an interbranch cooperation between shipbuilding and civil engineering. Flensburger Shipyard, Bauhaus-University Weimar, Ruhr-University Bochum, SimPlan AG as a simulation consultancy and the Center of Maritime Technologies joined this cooperation. Outfitting processes in shipbuilding and construction industry bear a high resemblance to each other. The same restrictions have to be considered such as dependencies between outfitting tasks, availability of resources 


\section{Steinhauer and Soyka}

and required work spaces as well as changing paths for transportation. In addition the planners have to answer similiar questions: how to find a practicable schedule with sufficiently utilized equipment and employees satisfying principal guidelines. In the interbranch team of SIMoFIT methods for outfitting simulation are developed further and used in various fields. One of the major steps forward was the adaption of the constraint satisfaction method to the simulation. Complex dependencies in the production flow can now be modeled and considered in the simulation (Beißert, König and Bargstädt 2007, König et al. 2007).

\subsection{Simulation Data Acquisition}

The most crucial point of using simulation for production planning and control in one-of-a-kind processes not only in shipbuilding is the acquisition of the required data. The data about the product or the planned production method is often not or not completely available when production starts. Furthermore, even the existing data might not be in the sufficient format for the simulation

Because the availability and acquisition of input data is the major obstacle in using simulation at shipyards basic research was required in this field. From October 2009 to September 2011 the GeneSim project (Generic Data and Model Management for Production Simulation in Shipbuilding) funded by the German ministry of economy and technology (FKZ 03SX274) focused on solutions for these kind of problems (Steinhauer 2010). The GeneSim consortium covered a variety of shipyards working on completely different types of ships like freight ships, passenger ferries, yachts or submarines. This group of shipyards was reasonably completed by a company very experienced in simulation consultancy and a university for the scientific support. All partners in GeneSim are users of STS for simulation modeling.

In the GeneSim project the data required for simulation of production processes in shipbuilding was defined and structured in a generic way. The data requirements of the simulation were derived by the data structure within STS and the applications at the participating shipyards. Strategies for importing and exporting data to that data structure were developed and methods for verifying and validating the data as well as the models were defined. At the end of the project the concepts were validated on different scenarios from production in shipbuilding.

The data structure developed in GeneSim was afterwards adopted by the simulation partners from construction industries and is now maintained and developed further in the interbranch cooperation SIMoFIT.

\subsection{Application Fields for Simulation at Flensburger}

At Flensburger, simulation is being applied in many ways as shown in Figure 2. As the starting point for the introduction of the simulation, projects for shipyard development were to be supported. For this purpose a tool was required to evaluate production processes, to reveal bottlenecks, to assure the intended productivity, and to compare possible alternatives. From the time the simulation team was established up to the present day all investment projects have been supported by the simulation, the most extensive one was the design and integration of a new panel line.

After having built and used simulation models in investment projects the usage of that models in production planning and control became the focal point of interest. The specific challenges of one-of-a-kind production can be met successfully by simulation. The strategy called Simulation Aided Production Planning (SAPP) was developed and implemented.

The simulation is now established as the main tool for supporting decisions in production and logistics at Flensburger Shipyard. In addition to using the simulation tools for internal projects and to the development of simulation tools for operation in planning and control the simulation team at Flensburger Shipyard also provides services in the field of simulation for other companies not only in maritime business. 

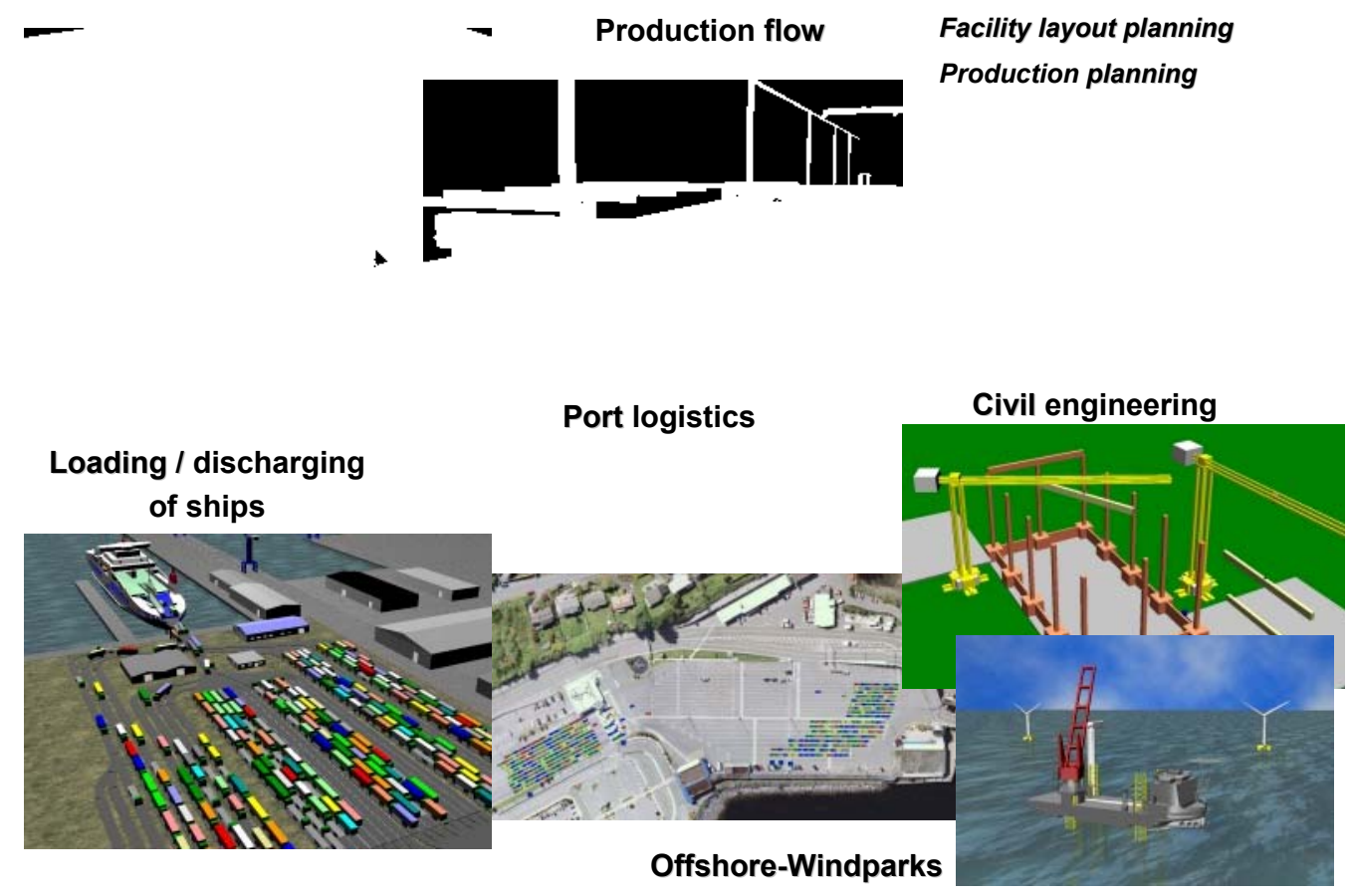

Figure 2: Application fields of simulation at Flensburger

At Flensburger Shipyard simulation is also used in the early design phase of a ship to evaluate loading and discharging scenarios or port logistics. This is part of Flensburger's strategy not only to build ships but to develop solutions for the logistical challenges of the customers.

\section{SIMULATION AIDED PRODUCTION PLANNING (SAPP)}

Simulation Aided Production Planning integrates the simulation technology into all phases of the process of production planning and control which are shown in principle in Figure 3. In the strategic planning phase the production program for a ship is defined based on the early design. The tactical planning leads to detailing the plan and adjusting resources according to the current production status. In operative control the foremen on the shop floor implement the plans and react on possible disturbances like lost material or machine breakdowns.

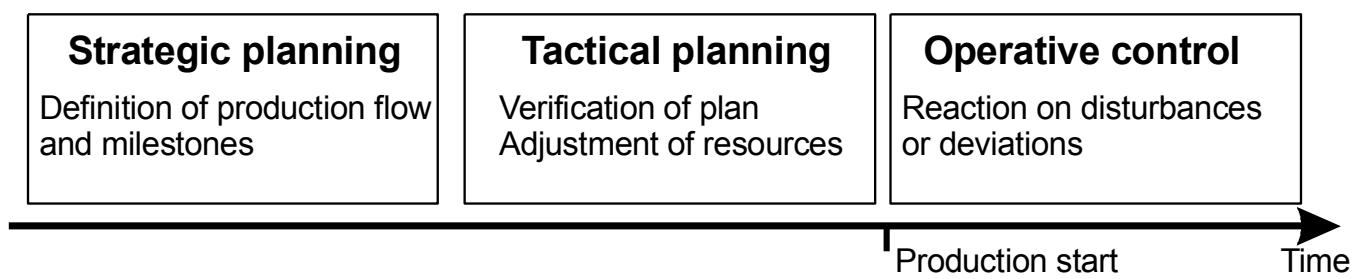

Figure 3: Phases of production planning in shipbuilding

Simulation serves as an integral part of the planning process. The plan can be evaluated and substantially improved in all planning phases, always based on the current data from design and production (Figure 4). This does not only increase the quality and flexibility of the planning process but also the reliability of the plan. 


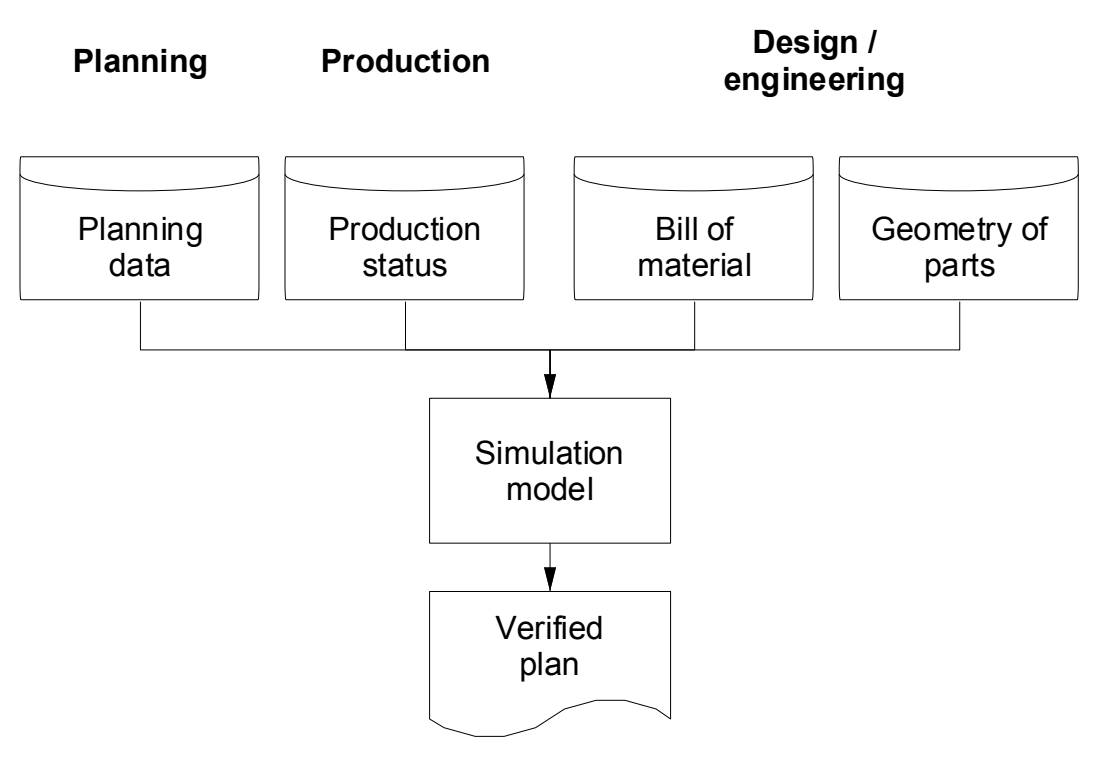

Figure 4: Data flow for SAPP

There are various advantages of SAPP: first of all the evaluation of the plan can be done considering all dynamic interactions between the product and the production. Alternative planning scenarios can be generated and evaluated quickly so a rather cost-efficient plan can be detected.

Another advantage is the improvement in communicating the plan. The planner can show the foremen or the worker the planning results and the impact on the production flow using the simulation output. Animations can play an important role in this respect. Because simulation models should be validated and committed by the production management before they are used, the simulation acts as an objective decision basis. This helps avoiding discussions that are not motivated by technical problems.

The flexibility in planning increases drastically by using SAPP. The simulation is linked to the current design and production situation. Therefore the plan can be adapted to changes in the product or in the production situation easily and the impact of these changes can be evaluated very quickly.

The earlier the simulation is to be used in the planning process the more uncertain the product data gets. In these early planning phases part descriptions are not available and the bill of material is not yet determined in detail. Therefore, an internal project called "DigiMeth" had been carried out at Flensburger to semi-automatically generate an assembly tree using all of the existing part information at any time of the design process.

SAPP also means the use of simulation not only by experts but by every planner and foreman involved. Therefore application specific user interfaces are used for showing and editing the simulation input, changing the parameters and analyzing and presenting the results of the simulation runs. Before the implementation of the tools not only the planners but also every involved foreman received a training in the basic simulation software and the STS to provide them with fundamental knowledge about simulation and it's handling. This training created a much better acceptance of simulation in the planning offices and on the shop floor

Certainly, simulation can not prevent a shipyard from disturbances. Still machines break down, material is lost or workers are not available. But the impact of these disturbances can be considered in the simulation model easily as a basis for the next simulation runs. Therefore, the impact of disturbances can be evaluated very quickly and thoroughly by SAPP.

Following the modeling process at Flensburger several applications for SAPP have been developed for the different production areas (Figure 5). These applications are standardized and implemented in a 


\section{Steinhauer and Soyka}

software environment called the Simulation Database. The single applications are used separately within tactical and operative planning and can be combined for strategic or holistic analysis.

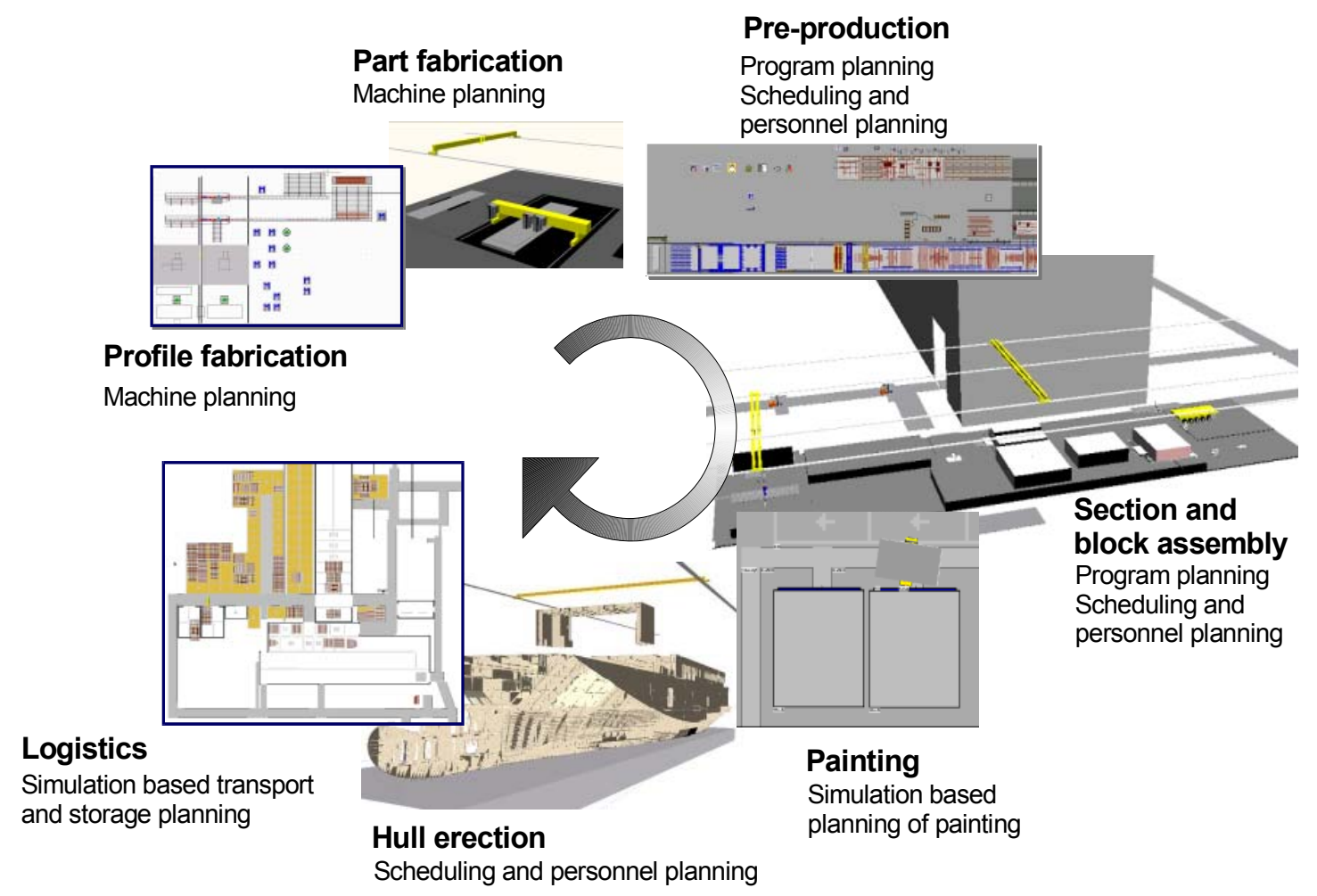

Figure 5: SAPP applications at Flensburger

In part fabrication, the detailed machine planning is based on simulation. Two applications are implemented, one for profile fabrication by robot lines and the other one for plate fabrication by cutting machines and manual workplaces. The simulation application assures sufficient delivery dates for the parts in the assembly stations causing low costs.

The layout of the panel line was influenced by limited space in the existing production hall. The use of simulation during all design stages allowed the installation of a very sophisticated and innovative plant combination that helped to halve the required workforce while keeping the same throughput and increasing the quality of the manufactured panels. After the installation of the production line this production area has been the first that included the SAPP strategy. The corresponding planner carries out simulation runs weekly to determine the required workforce of each of the related worker pools. These results are discussed with the foremen and are the basis for the personnel planning. In addition to this the production program is verified on the long term as well and enhanced by evaluation of different production sequences. This application of the simulation model is conducted at an average of once in three month.

The simulation of block assembly posed new challenges for the adaptability of the simulation tools. At Flensburger Shipyard a block represents a part of the ship that has been pre-outfitted but is still transportable. This production area is designed as site production. The different sizes and process sequences of the blocks require a completely different simulation approach, since here the work is based on very product specific constraints. Since the simulation model is able to use process data, that has been defined during the method planning process and was translated automatically into constraints and process patterns the planner is able to use the simulation without the need for complex model adjustments. Apart from the functionalities described for the panel line one of the major benefits of this simulation application is the verification of lead time for the blocks, since the simulation includes the dynamic influencing values 


\section{Steinhauer and Soyka}

which allow a much more precise forecast when compared to conventional methods. The planner is able to define a much more accurate and reliable schedule for space allocation, improving the throughput and reducing the fault liability of this work area.

\section{APPLICATION EXAMPLE: SEQUENCING IN PART PRODUCTION}

In 2006, an investment project was carried out at Flensburger to redesign the part fabrication. In this production area, small to medium sized parts are cut by a cutting device from $12 \mathrm{~m} \times 3 \mathrm{~m}$ steel plates. Due to the fact, that within the complex system ship most steel parts are unique, the parts nested on the plates differ a lot according to number, size and shape.

In the existing part fabrication the throughput was not sufficient which caused overtime and the need for subcontracting. The goal of the investment project was to substitute the underwater cutting machine increasing the throughput by $50 \%$ and reducing the man hours. On the technological side the signing procedure should be included as an automated process. Technologically challenging was the fact, that the new plant concept should be able to cover blasting, marking and signing processes on both sides of the plates.

The blasting, marking, signing and cutting of plates was achieved in a completely new production concept as shown in Figure 6. The cutting process is separated from the others by using different machines. The signing/marking/blasting portal works in junction with a vacuum lifting device to process both sides of the plate.

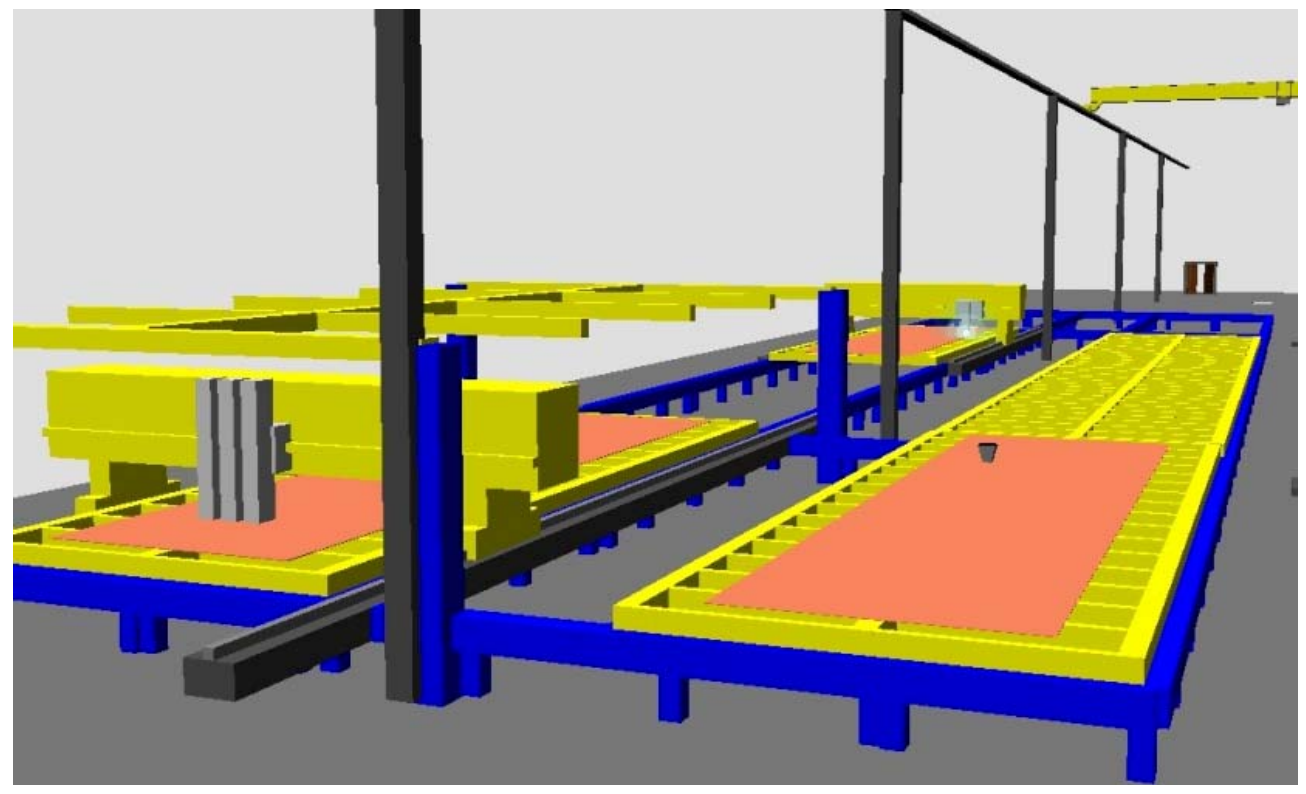

Figure 6: Simulation model of the part fabrication

The development process of the new part manufacturing layout had closely been supported by simulation. All of the scenarios based on different ideas with respect to technology or logistics were modeled and evaluated in the simulation. Hence, a suitable and feasible layout fitting in the existing manufacturing hall could be found to achieve the different goals in terms of performance, quality and costs. Since the simulation model uses the same numeric data as the real machines, the simulation results proved to be of sufficient accuracy not only for layout planning but also for production planning and control.

After the installation of the new machine the simulation model of the layout phase has been adapted for a usage in the SAPP-concept of the FSG. Plates to be processed within this manufacturing area have to be transported by truck from an external storage area. The trailers have to be ordered ten working days in advance, which is done by an automatic process according to date required and plate weight using a 


\section{Steinhauer and Soyka}

simple weight disposition of the trailers to minimize transports. Depending on the plate thickness the number of plates on one trailer ranges from 7 to 13. In the external storage area all plates are loaded in a specified sequence, since some of the production areas of Flensburger rely on the order of the plates.

Due to the boundary conditions in one-of-a-kind production the workload of machines can differ by up to $500 \%$ during a daily part spectrum. This results in moving bottlenecks. Hence, the order of the plates has a significant impact on the productivity of the fabrication station. To improve the throughput of part fabrication, the sequence of the plates is to be optimized using the existing simulation model.

The model has been supplemented with the ISSOP interface available in STS. ISSOP by Dualis IT Solutions is a software tool that provides seven different mathematic optimization algorithms cooperating and competing with each other to solve different optimization tasks. The interface tool between the STS and ISSOP has been developed during the national founded research project SIMGO (Steinhauer and Wagner 2008).

The simulation model automatically analyses the throughput of the system considering the sequence of plates and transfers the information to the connected ISSOP tool. ISSOP varies the sequence using the optimizing procedures and initiates a new simulation run. A number of approximately 2000-3000 simulation runs has been determined as sufficient to improve the throughput significantly (Figure 7). This takes approximately two hours of real time. An improvement of $7-12 \%$ can be achieved by this process before the material order phase. The simulation process is executed on a dedicated simulation server, saving computing capacity of the planner's own computer. The part fabrication is able to process the load of two to three trailers per day. The planner does the optimization procedure in parallel. After a time of approximately three hours the results are available on the simulation server. The user has the possibility to export the best calculated result to the material control system or to continue the optimization, if he decides it to be necessary. Since the material handling in the storage area is done in the ordered sequence anyway, no additional costs occur for sorting the plates according to the determined sequence.

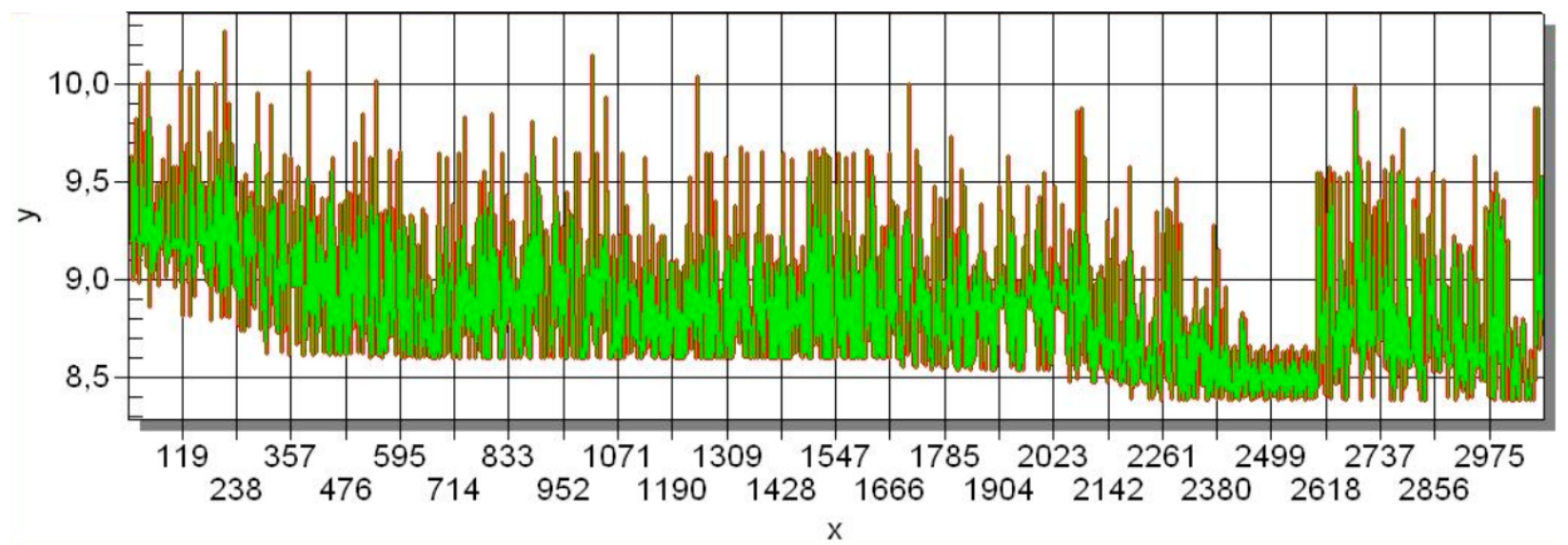

Figure 7: Example for reduction of lead time in part production $(\mathrm{x}=$ simulation runs, $\mathrm{y}=$ lead time $[\mathrm{h}])$

The plate sequence determined for a trailer to be delivered is transferred to the material control system as shown in Figure 8. The ordered trailer is packed in the requested order by the plate supplier. With an approximate effort of half a person hour per day the planner can improve the throughput of this production area by $10 \%$ in average.

It would be possible to increase the improvement, if the number of plates for optimization would be increased, expanding the search area to several trailers. This would result in a multi-criteria optimization. Since the transport costs should not increase this possibility has been refrained from in favour of the chosen concept, because no additional costs occur while the throughput time has been reduced with help of an automated process. 


\section{Steinhauer and Soyka}

The simulation model has been shaped into a tool for the responsible planner. Controlled by an easy to use interface the planner is able to choose which trailers' plate sequence should be improved.

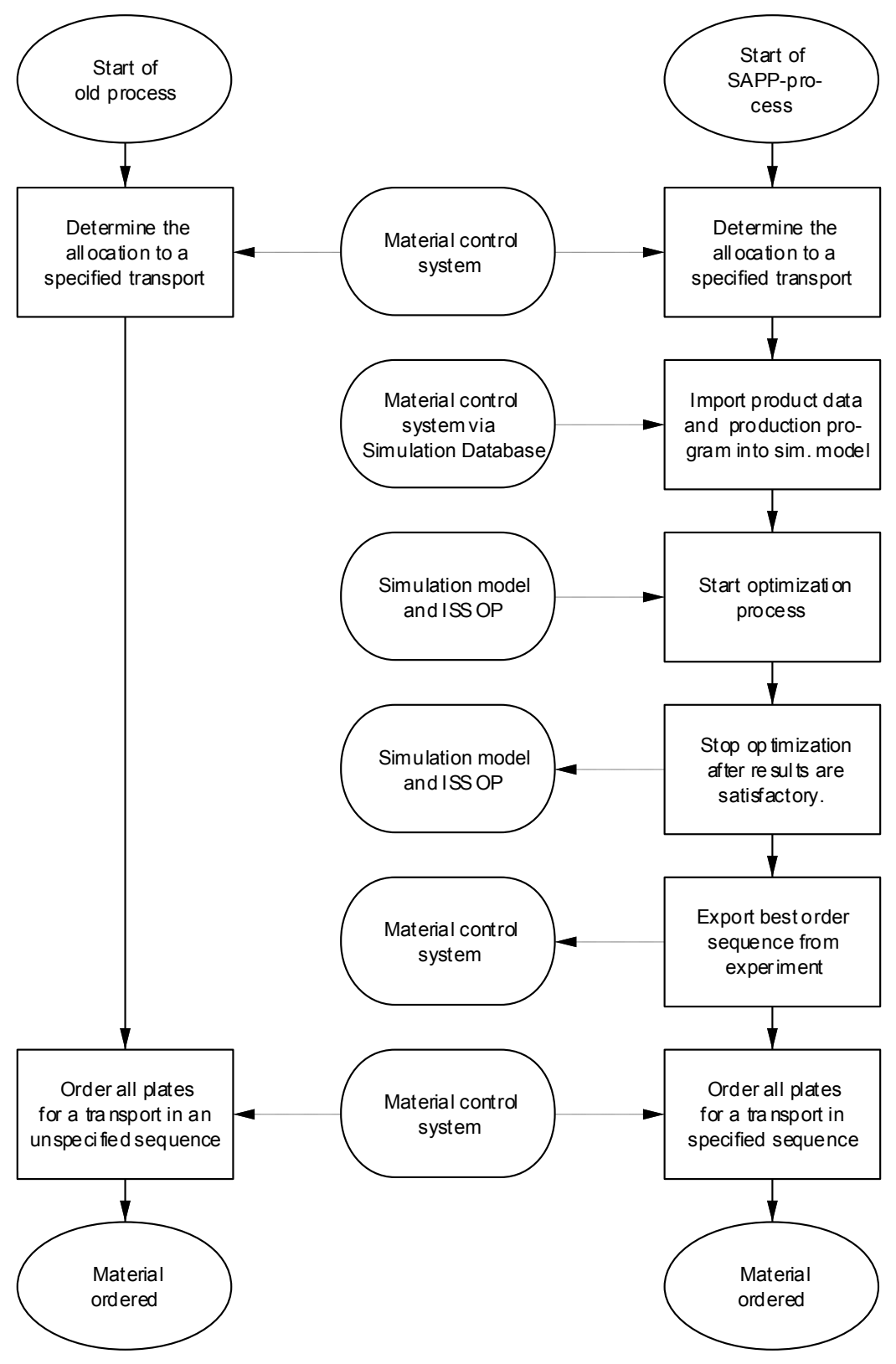

Figure 8: Comparison of old and SAPP plate order process

\section{CONCLUSION}

The simulation applications at Flensburger Shipyard especially in production planning show the potentials that can be tapped in one-of-a-kind production. Basis for the simulation are a sufficient modeling approach on the one hand and methods for data acquisition on the other hand. Both simulation model and database should be integrated in a tool environment usable for the planner or foreman. Hence, at Flensburger Shipyard the Simulation Toolkit Shipbuilding (STS) has been developed to cover the modeling re- 


\section{Steinhauer and Soyka}

quirements of site production and complex assembly processes. For collecting and preparing the required data about the product, the production processes and the resources a generic approach was created based on the experiences of developing and using the Simulation Database at Flensburger. The simulation tools are now used in various applications covering production development and production planning and control. By the continuous usage of simulation in the production planning the reliability of the plan and the productivity can be significantly increased.

\section{REFERENCES}

Beißert ,U., König, M., and Bargstädt, H.-J. 2007. „Constraint-Based Simulation of Outfitting Processes in Building Engineering", In proceedings of $24^{\text {th }}$ W78 Conference, Maribor, Slovenia

König, M, Beißert, U., Steinhauer, D., and Bargstädt, H.-J. 2007. „Constraint Based Simulation of Outfitting Processes in Shipbuilding and Civil Engineering“, In proceedings of $6^{\text {th }}$ EuroSim Congress on Modeling and Simulation

Steinhauer, D., and Wagner L. 2008. „Simulation-supported Optimisation in Maritime Production Planning" In Advances in Simulation for Production and Logistics Applications, Edited by M. Rabe, 459468, Stuttgart, Fraunhofer IRB Verlag

Steinhauer, D. 2010. "GeneSim - Development of a Generic Data Model for Production Simulation in Shipbuilding“, In proceeding of $9^{\text {th }}$ Conference on Computer and IT Applications in the Maritime Industries, Edited by Volker Bertram, 304-310, Technische Universität Hamburg-Harburg

Steinhauer, D. 2011. "The Simulation Toolkit Shipbuilding (STS) - 10 Years of Cooperative Development and Interbranch Applications." In proceedings of $10^{\text {th }}$ Conference on Computer and IT Applications in the Maritime Industries, Edited by Volker Bertram, 453-465, Technische Universität Hamburg-Harburg

\section{AUTHORS BIOGRAPHIES}

DIRK STEINHAUER studied mechanical engineering at University of Hannover, Germany specializing on production technology and quality management. Since 1995, he had been working in the Production Technology department at Flensburger Schiffbau-Gesellschaft mbH \& Co. KG. He managed various projects concerning facility layout planning and organizational development before he focused on simulation in production and logistics in 1997. As head of the simulation team he is responsible for Flensburger's simulation activities containing amongst others the work on the Simulation Toolkit Shipbuilding (STS), the support of investment projects and the development of applications for production planning and control. He also coordinates the work of the international cooperative associations SimCoMar and SIMoFIT. Since 2003, Dirk Steinhauer lectures on ship production at Technical University of Berlin. His email address is steinhauer@fsg-ship.de.

MICHAEL SOYKA is a simulation expert in the simulation team of Flensburger Schiffbau-Gesellschaft $\mathrm{mbH} \&$ Co. KG (FSG). He studied mechanical engineering at University of Applied Sciences in Flensburg specializing on energy management and power plant technology. Besides development of the Simulation Toolkit for Shipbuilding (STS) he has carried out several simulation projects in the field of production development and planning. Since 2003 he is responsible for simulation studies of loading and discharging operations of vessels to improve the design capabilities of the FSG. His email address is soyka@fsg-ship.de. 